DOI: $10.1002 /$ celc. 201901584

Full Paper

Received: 25.^September.^2019

Revised: 12.November 2019

Accepted Article published: 29.November 2019

\title{
Electrocatalysis of Oxygen on Bifunctional Nickel-Cobaltite Spinel
}

Dr. Cinthia Alegre, ${ }^{[a, b] *}$ Dr. Concetta Busacca, ${ }^{[b]}$ Dr. Alessandra Di ${ }^{\wedge \wedge}$ Blasi, ${ }^{[b]}$ Dr. Orazio $\mathrm{Di}^{\wedge \wedge}$ Blasi, ${ }^{[\mathrm{b}]}$ Dr. Antonino ${ }^{\wedge \wedge}$ S. Aricò,${ }^{[b]}$ Dr. Vincenzo Antonucci, ${ }^{[b]}$ Dr. Vincenzo Baglio0000-0002-0541-7169 ${ }^{[\mathrm{b}] *}$

[a] <orgDiv/>Instituto de Carboquímica (ICB) $<$ orgName/>Consejo Superior de Investigaciones Científicas (CSIC)

$<$ street/ $>$ C/. Miguel Luesma Castán, $4 .<$ postCode/ $>50018<$ city/ $>$ Zaragoza

$(<$ country/>Spain)

E-mail: cinthia@icb.csic.es

[b] <orgDiv/>Istituto di Tecnologie Avanzate per l'Energia "Nicola Giordano" (ITAE) $<$ orgName/>Consiglio Nazionale delle Ricerche (CNR)

$<$ street/ $>$ Salita S. Lucia sopra Contesse, 5 . $<$ postCode/ $>98126<$ city/ $>$ Messina $(<$ country/>Italy)

E-mail: baglio@itae.cnr.it

E-mail: dummy@delete.me

$<$ spi $>$ An invited contribution to a Special Collection dedicated to Giornate dell'Elettrochimica Italiana 2019 (GEI2019)

carbon nanofibers

spinel

oxygen reduction

oxygen evolution

bifunctional oxygen electrodes 
Spin me round: Transition-metal-based materials are among the most active and durable catalysts for the effective electrocatalysis of oxygen-related reactions. $\mathrm{NiCo}_{2} \mathrm{O}_{4}$ spinel supported on electrospun carbon nanofibers presents good performance and bifunctionality for both the oxygen reduction reaction (ORR) and oxygen evolution reaction (OER). Oxidized species $\left(\mathrm{Ni}^{3+}\right.$ and $\left.\mathrm{Co}^{3+}\right)$ enhance OER, whereas lower oxidation states $\left(\mathrm{Ni}^{2+}, \mathrm{Co}^{2+}, \mathrm{Ni}^{0}\right.$ and $\mathrm{Co}^{0}$ ) enhance ORR.

Transition-metal-based materials are among the most active and durable catalysts for the effective electrocatalysis of oxygen-related reactions. Herein, we present a study on bifunctional catalysts as air electrodes aimed at metal-air batteries based on nickel and cobalt spinel $\left(\mathrm{NiCo}_{2} \mathrm{O}_{4}\right)$ supported on electrospun carbon nanofibers. The physicochemical features of these transition-metal-based catalysts are essential for the understanding of their electrochemical activity. Results show that the major presence of oxidized $\mathrm{Ni}$ and Co species $\left(\mathrm{Ni}^{3+}\right.$ and $\left.\mathrm{Co}^{3+}\right)$ produces higher activity for the oxygen evolution reaction (OER), whereas lower oxidation states of the metals $\left(\mathrm{Ni}^{2+}, \mathrm{Co}^{2+}, \mathrm{Ni}^{0}\right.$ and $\left.\mathrm{Co}^{0}\right)$ together with the presence of $\mathrm{N}-$ doped carbon lead to enhanced oxygen reduction reaction (ORR) performance. This study highlights the importance of designing catalysts in terms of crystallographic structure and proper oxidation states of the elements for maximizing their performance.

\section{Introduction}

A new way to produce and store electrical energy is necessary to address future energy demands and reduce polluting emissions.$^{[1,2]}$ Rechargeable alkaline metal-air batteries can be considered one of the most promising next energy systems owing to their extremely high energy densities..$^{[3--7]}$ These make them particularly interesting for applications in electricalenergy storage systems for coupling intermittent renewable energy sources into smart energy grids. However, this kind of batteries requires very efficient and durable bifunctional electrocatalysts to accelerate the kinetics of oxygen reduction reaction (ORR), taking place during the discharge, and oxygen evolution reaction (OER), occurring during charging of the battery. ${ }^{[8--12]}$ Nowadays, the state-of-the-art catalysts are Pt-based nanoparticles for the ORR 
and $\mathrm{IrO}_{2}$ for the OER. ${ }^{[13--15]}$ However, the high cost of these electrocatalysts makes these materials unattractive. To replace these expensive noble catalysts, low cost alternatives such as transition metal oxides have been considered. ${ }^{[16-22]}$ Among them, cobalt-based oxides are envisaged as the most active catalysts for the electrocatalysis of oxygen. ${ }^{[23-30]}$ Spinel-type $\mathrm{Co}_{3} \mathrm{O}_{4}$ nanoparticles have received a great deal of attention as bifunctional materials for oxygen reactions due to their higher intrinsic activity (compared to noble metals) and suitable stability, in particular for the OER. ${ }^{[25,26,31,32]}$ However, the electrical conductivity of these materials is not appropriate for the application in metal-air batteries. Ni and other transition metals can partially replace $\mathrm{Co}$ atoms in the $\mathrm{Co}_{3} \mathrm{O}_{4}$ spinel structure introducing electronic levels in the band gap, improving in such a way its electronic conductivity while promoting water electro-adsorption and oxygen evolution. ${ }^{[33-37]}$ Another approach is supporting transition metals on conductive and graphitic carbon nanomaterials, in order to maintain suitable stability under cycling operation. In fact, composite catalysts based on transition metal oxides and carbon (in particular, nitrogen-doped carbonaceous material) have received increasing attention owing to their synergistic catalytic activity. ${ }^{[33,38-42]}$ Recently, our group investigated electrospun carbon nanofibers (CNF) decorated with both cobalt oxide and metallic cobalt $(\mathrm{CoO}<\mathrm{C}->\mathrm{Co} / \mathrm{CNF})^{[25]}$ or loaded with nickel and cobalt (both in the metallic and oxide forms), ${ }^{[4]}$ as bifunctional air electrodes, which presented good reversibility and stability. In the present research the latter catalyst (NiCo-loaded CNFs), ${ }^{[43]}$ was further oxidized with the aim of synthesizing the pure spinel structure $\left(\mathrm{NiCo}_{2} \mathrm{O}_{4}\right)$ supported on the electrospun CNFs. The performance for the oxygen electrocatalysis (i.^e., water splitting and oxygen reduction) of the catalyst was evaluated and compared to the previously reported NiCo-loaded CNF catalyst in order to elucidate the performance as a function of the oxidation state and the crystallographic structure of $\mathrm{Ni}<\mathrm{C}->\mathrm{Co}$ based materials.

\section{Results and Discussion}


The XRD pattern of $\mathrm{NiCo}_{2} \mathrm{O}_{4} / \mathrm{CNF}\left(\right.$ Figure ${ }^{\wedge \wedge} 1<$ figr $1>$ ) shows characteristic diffraction peaks of a cubic spinel structure (JCPDS card No: 01073-1702). A peak centered at $2 \theta=26.3^{\circ}$ is ascribed to the (002) plane of graphitic carbon. ${ }^{[44,45]}$ The $\mathrm{NiCo}_{2} \mathrm{O}_{4}$ crystallite size, calculated by the Scherrer's equation, is about $12^{\wedge \wedge} \mathrm{nm}$.

The TG/DSC profiles of electrospun NiCo-loaded CNF are shown in Figure $^{\wedge} 2<$ figr $2>$ with the only purpose to elucidate the selected oxidation temperature to obtain $\mathrm{NiCo}_{2} \mathrm{O}_{4} / \mathrm{CNF}$. A large weight loss of about $60^{\wedge} \%$ in the temperature range $400--$ $500^{\wedge} \mathrm{C}$ is due to the decomposition of carbon nanofibers. Therefore, we considered the temperature value of $350^{\wedge \circ} \mathrm{C}$ suitable for the thermal oxidation treatment of electrospun NiCo-loaded CNF avoiding the decomposition of carbon nanofibers structure. The TG/DSC analysis profile of $\mathrm{NiCo}_{2} \mathrm{O}_{4} / \mathrm{CNF}$ is also reported in Figure ${ }^{\wedge \wedge} 2<x$ figr $2>$ in order to evaluate the amount of $\mathrm{NiCo}_{2} \mathrm{O}_{4}$ in the composite material. The TG curve shows a significant weight loss (about $60^{\wedge \wedge} \mathrm{wt}^{\wedge 0} \%$ ) associated to an exothermic peak in the temperature range 320 -$400^{\wedge} \mathrm{C}$ due to the complete oxidation of carbon nanofibers. The amount of residual $\mathrm{NiCo}_{2} \mathrm{O}_{4}$ in the composite material is about $40^{\wedge \wedge} \mathrm{wt}^{\wedge} \%$.

Figure $^{\wedge \wedge} 3<$ figr $3>$ shows TEM images and the particle size distribution of the electrospun spinel $\mathrm{NiCo}_{2} \mathrm{O}_{4} / \mathrm{CNF}$. The image at a lower magnification (Figure ${ }^{\wedge \wedge} 3<x$ figr $3>a$ ) shows the presence of porous carbon nanofibers with well-distributed $\mathrm{NiCo}_{2} \mathrm{O}_{4}$ nanoparticles. The diameter of the nanofibers is in the range of $100--200^{\wedge} \wedge \mathrm{nm}$. The higher magnification images (Figure ${ }^{\wedge \wedge} 3<$ xfigr $3>b--3 c$ ) further confirm the good dispersion of $\mathrm{NiCo}_{2} \mathrm{O}_{4}$ nanoparticles in the graphitic matrix of carbon nanofibers. The lattice fringes, indicated in Figure ${ }^{\wedge} 3<x$ figr $3>$ c , can be indexed to the (111) crystal plane of $\mathrm{NiCo}_{2} \mathrm{O}_{4}$ as also revealed by XRD. The particle size distribution was obtained by calculating the particle average diameter of one hundred selected particles (Figure ${ }^{\wedge} 3<\mathrm{xfigr} 3>\mathrm{d}$ ). The peak value of the distribution 
curve was taken as an average particle size of about $12^{\wedge \wedge} \mathrm{nm}$, in agreement with the value obtained from XRD.

The textural properties of $\mathrm{NiCo}_{2} \mathrm{O}_{4} / \mathrm{CNF}$ were investigated by $\mathrm{N}_{2}$ physisorption, recording the adsorption/desorption isotherms and using the Brunauer-Emmett-Teller (BET) method to calculate the surface area $\left(\mathrm{S}_{\mathrm{BET}}\right)$. The $\mathrm{S}_{\mathrm{BET}}$ and total pore volume were about $153^{\wedge \wedge} \mathrm{m}^{2 \wedge . \wedge} \mathrm{g}^{<\mathrm{M}->1}$ and $0.311^{\wedge \wedge} \mathrm{cm}^{3 \wedge . \wedge} \mathrm{g}^{<\mathrm{M}->1}$, respectively. The lower surface area of $\mathrm{NiCo}_{2} \mathrm{O}_{4} / \mathrm{CNF}$ compared to the NiCo-loaded CNF $\left(309^{\wedge \wedge} \mathrm{m}^{2 \wedge} \cdot \wedge \mathrm{g}^{<\mathrm{M}->1}\right)$ could be attributed to the thermal treatment at $350^{\wedge \circ} \mathrm{C}$ in air which leads to particle agglomeration as well as to a carbon loss (the amount of residual carbon for the present catalyst after the thermal treatment is about $40^{\wedge} \%$ compared to $20^{\wedge} \%$ of the NiCo-loaded CNF starting material).

X-ray photoelectron spectroscopy (XPS) measurements were performed in order to investigate the surface composition and oxidation state of the species forming the electrospun $\mathrm{NiCo}_{2} \mathrm{O}_{4} / \mathrm{CNF}$. Table ${ }^{\wedge} 1<$ tabr $1>$ reports the atomic concentrations of C1s, N1s, O1s, Co2p and Ni2p. The Ni/Co atomic ratio is about 0.5 and the sum of the $\mathrm{Co} / \mathrm{O}$ and $\mathrm{Ni} / \mathrm{O}$ atomic ratios is about 0.76 in accordance with the $\mathrm{NiCo}_{2} \mathrm{O}_{4}$ stoichiometric compound. The nitrogen species were slightly more abundant in the spinel type material than in the NiCo-loaded CNF sample.

Figure $^{\wedge \wedge} 4<$ figr $4>$ shows the XPS deconvolution curves of the $\mathrm{O} 1 \mathrm{~s}, \mathrm{C} 1 \mathrm{~s}$ and $\mathrm{N} 1 \mathrm{~s}$ orbitals for the $\mathrm{NiCo}_{2} \mathrm{O}_{4} / \mathrm{CNF}$ spinel material. The curve fitting of O1s spectrum (Figure ${ }^{\wedge} 4<$ xfigr $4>$ a) presents five peaks. The first peak centered at $529.5^{\wedge \wedge} \mathrm{eV}$ can be attributed to the metal-oxygen bonds $(\mathrm{M}<\mathrm{C}->\mathrm{O})$. The peak at $530.5^{\wedge \wedge} \mathrm{eV}$ indicates the presence of hydroxyl groups $(<\mathrm{C}->\mathrm{OH})$ on the surface of $\mathrm{NiCo}_{2} \mathrm{O}_{4} / \mathrm{CNF}$. The peak at $531.5^{\wedge \wedge} \mathrm{eV}$ is due to the presence of oxygen ions $\left(\mathrm{O}_{2}^{<\mathrm{M}->}\right)$ in low coordination at the surface. A further peak centered at $532.5^{\wedge \wedge} \mathrm{eV}$ could be ascribed to the presence of adsorbed water on the surface. ${ }^{[46]}$ The presence of $\mathrm{C}<\mathrm{C}->\mathrm{OH}$ phenolic groups was recorded at $533.6^{\wedge \wedge} \mathrm{eV} .{ }^{[43]}$ 
The deconvolution analysis of $\mathrm{C} 1 \mathrm{~s}$ spectrum leads to five peaks (Figure ${ }^{\wedge \wedge} 4<\mathrm{xfigr} 4>\mathrm{b}$ ) corresponding to different carbon species. The main peak at $284.6^{\wedge \wedge} \mathrm{eV}$ is normally ascribed to graphitic carbon $(\mathrm{C}<\mathrm{C}=>\mathrm{C}$ sp2 $)$ while the peak at $285.5^{\wedge} \mathrm{eV}$ is attributed to amorphous carbon $(\mathrm{C}<\mathrm{C}->\mathrm{C}$ sp3 $)$. The peaks at $286.5^{\wedge \wedge} \mathrm{eV}$ and $287.6^{\wedge \wedge} \mathrm{eV}$ can be associated with species of carbon bonded to oxygen and nitrogen species designated as $\mathrm{C}<\mathrm{C}->\mathrm{O} / \mathrm{C}<\mathrm{C}->\mathrm{N}$ and $\mathrm{C}<\mathrm{C}=>\mathrm{O} / \mathrm{C}<\mathrm{C}=>\mathrm{N}$, respectively. The smaller peak at $289.6^{\wedge \wedge} \mathrm{eV}$ is probably due to the presence of carboxyl groups $(\mathrm{O}<\mathrm{C}=>\mathrm{C}<\mathrm{C}->\mathrm{O})$ on the surface. ${ }^{[47]}$

The N1s spectrum (Figure ${ }^{\wedge} 4<$ xfigr $4>c$ ) was deconvoluted in five peaks which can be associated to different nitrogen species such as the pyridinic- $\mathrm{N}\left(398.2^{\wedge \wedge} \mathrm{eV}\right)$, pyrrolic-N $\left(400.1^{\wedge \wedge} \mathrm{eV}\right)$, graphitic-N $\left(401.4^{\wedge \wedge} \mathrm{eV}\right)$ and pyridine-N-oxide $\left(402.7^{\wedge \wedge} \mathrm{eV}\right) .{ }^{[48]} \mathrm{A}$ further peak at about $399^{\wedge} \mathrm{eV}$ indicates the presence of $\mathrm{Co}<\mathrm{C}->\mathrm{Nx}$ type species. Figure ${ }^{\wedge} 4<<\mathrm{xfigr} 4>\mathrm{d}$ reports a histogram of the nitrogen contents in both $\mathrm{NiCo}_{2} \mathrm{O}_{4} / \mathrm{CNF}$ and NiCo-loaded CNF samples. It should be noted that the $\mathrm{NiCo}_{2} \mathrm{O}_{4} / \mathrm{CNF}$ has a higher amount of nitrogen in the form of pyridinic-N, graphitic-N and $\mathrm{Co}<\mathrm{C}->\mathrm{Nx}$ with respect to NiCo-loaded CNF sample. These nitrogen groups are considered as ORR active sites.

In Figure ${ }^{\wedge} 5<$ figr $5>$ the deconvolution spectra of Ni2p and Co2p orbitals are shown. The deconvolution of Ni2p spectrum (Figure ${ }^{\wedge \wedge} 5<x$ figr $5>a$ ) shows six peaks. The peaks at 854.5 and $871.5^{\wedge \wedge} \mathrm{eV}$ are attributed to $\mathrm{Ni}^{2+}$ ions located in the octahedral sites of the spinel structure while the peaks at 856.1 and $873.8^{\wedge \wedge} \mathrm{eV}$ are assigned to $\mathrm{Ni}^{3+}$ ions.${ }^{[49]}$ Moreover, two "shake-up" satellite peaks can be identified at binding energies of 862 and $880^{\wedge} \mathrm{eV}$. These satellite peaks were fitted considering only one broad line but include the contribution of both $\mathrm{Ni}^{2+}$ and $\mathrm{Ni}^{3+}$ ions. ${ }^{[50]}$ As reported in Figure ${ }^{\wedge \wedge} 5<\mathrm{xfigr} 5>\mathrm{c}$, the $\mathrm{Ni}^{3+}$ ions are present in larger amount with respect to the $\mathrm{Ni}^{2+}$ ions, indicating that many active sites could be available for the OER. The Co2p spectrum (Figure ${ }^{\wedge} 5<$ xfigr $5>$ b) was fitted in nine deconvolution peaks. The peaks at 779.5 and $795^{\wedge} \mathrm{eV}$ are ascribed to the $\mathrm{Co}^{3+}$ ions while the peaks at 780.5 and 
$796^{\wedge} \mathrm{eV}$ are due to the presence of $\mathrm{Co}^{2+}$ ions. Two "shake-up" satellite peaks are also evident in the Co2p spectrum at a binding energy of about $787^{\wedge \wedge} \mathrm{eV}$ and $803^{\wedge \wedge} \mathrm{eV}$. Each satellite peak can be deconvoluted in two peaks due to the contribution of $\mathrm{Co}^{3+}$ and $\mathrm{Co}^{2+}$ ions. ${ }^{[51]} \mathrm{A}$ further peak at about $782^{\wedge \wedge} \mathrm{eV}$ can be associated with species of cobalt bonded to nitrogen $(\mathrm{Co}<\mathrm{C}$ $>\mathrm{N}_{\mathrm{x}}$ ). In Figure ${ }^{\wedge} 55<$ figr $5>$ d the amount of Co species present in $\mathrm{NiCo}_{2} \mathrm{O}_{4} / \mathrm{CNF}$ are reported. It is possible to observe that the $\mathrm{Co}^{2+}$ ions are in excess with respect to the $\mathrm{Co}^{3+}$ ions. As known, $\mathrm{Co}^{2+}$ ions play a fundamental role in the ORR catalytic process. ${ }^{[47]}$

Figure $^{\wedge \wedge} 6<$ figr $6>$ depicts the linear sweep voltammetry (LSVs) recorded in the GDWE in comparison with the NiCo-loaded CNF catalyst, studied in our previous work, ${ }^{[43]}$ and a noble metal-based catalyst,

$\mathrm{Pd} /$ Vulcan, synthesized as described elsewhere ${ }^{[15]}$ used as a reference material. The loading on the working electrode was the same for the three catalysts, $0.5^{\wedge \wedge} \mathrm{mg}^{\wedge} \mathrm{cm}^{<\mathrm{M}->2}$ of the active material ( $\mathrm{NiCo}, \mathrm{NiCo}_{2} \mathrm{O}_{4}$ or $\left.\mathrm{Pd}\right)$.

\subsection{Oxygen Reduction Reaction}

The two non-noble catalysts present similar performances for the oxygen reduction reaction $(\mathrm{ORR})$, Figure ${ }^{\wedge \wedge} 6<x$ figr6 $>$ a, whereas, as expected,

$\mathrm{Pd} /$ Vulcan presents the highest activity showing the best onset potential, $\mathrm{E}_{\text {onset }}=0.930^{\wedge \wedge} \mathrm{V}$ vs. RHE, as can be also ascertained from Table $\mathrm{e}^{\wedge} 2<\operatorname{tabr} 2>$.

Both NiCo-based materials exhibit very similar onset potential $\left(0.887^{\wedge \wedge} \mathrm{V}\right.$ for $\mathrm{NiCo}-$ loaded $\mathrm{CNF}$ and $0.861^{\wedge \wedge} \mathrm{V} \mathrm{NiCo}{ }_{2} \mathrm{O}_{4} / \mathrm{CNF}$ ), around $40--70^{\wedge \wedge} \mathrm{mV}$ lower than the one for $\mathrm{Pd} /$ Vulcan. This means that the overpotential for the ORR in the case of the noble metal catalyst is the lowest $\left(300^{\wedge \wedge} \mathrm{mV}\right.$, versus $343^{\wedge \wedge} \mathrm{mV}$ and $369^{\wedge \wedge} \mathrm{mV}$ for the NiCo-based species, NiCo-loaded $\mathrm{CNF}$ and $\mathrm{NiCO}_{2} \mathrm{O}_{4} / \mathrm{CNF}$, respectively). The differences in activity can be ascribed to different aspects. First, the best performance of the $\mathrm{Pd} / \mathrm{Vulcan}$ is due to the best 
intrinsic activity of the noble metal towards this reaction, in comparison to the catalysts based on non-noble transition-metals. Among the two NiCo-based materials, taking into account that the two catalysts show a similar crystallite size $\left(10--11^{\wedge \wedge} \mathrm{nm}\right.$ for the NiCo-loaded CNF and $12^{\wedge \wedge} \mathrm{nm}$ for the $\mathrm{NiCo}_{2} \mathrm{O}_{4}$ ), the different oxidation state for $\mathrm{Ni}$ and $\mathrm{Co}$ and the crystallographic structure can be the cause for the diverse catalytic activity. NiCo-loaded CNF catalyst presents a higher concentration of $\mathrm{Co}^{2+}$ ions $\left(63^{\wedge} \%\right.$ versus $51^{\wedge} \%$ for $\left.\mathrm{NiCo}_{2} \mathrm{O}_{4} / \mathrm{CNF}\right)$, recognized as active sites favoring the ORR ${ }^{\left[{ }^{[6]}\right.}$ Besides, the presence of both cobalt and nickel in their metallic form in the NiCo-loaded CNF is also responsible for the slightly enhanced activity for the ORR, as they participate as secondary active sites. ${ }^{[43]}$

\subsection{Oxygen Evolution Reaction}

The performance regarding the oxygen evolution reaction (OER) shows significant differences between the three catalysts. The spinel type material shows the highest activity for the OER, with a potential at $10^{\wedge \wedge} \mathrm{mA}^{\wedge} \mathrm{cm}^{<\mathrm{M}->2}$ of $1.453^{\wedge \wedge} \mathrm{V}$ vs. RHE (meaning an overpotential of $223^{\wedge \wedge} \mathrm{mV}$ ). This is one of the lowest values obtained within the current literature, although a straightforward comparison is not always feasible. For example, Bae $\mathrm{et}^{\wedge}$ al . obtained $\mathrm{Ni}<\mathrm{C}->\mathrm{Co}$ nanowires grown on a carbon fiber woven fabric. ${ }^{[52]}$ Their NiCobased material showed an overpotential of $302^{\wedge \wedge} \mathrm{mV}$ for the OER in a $1^{\wedge \wedge} \mathrm{M} \mathrm{KOH}$ solution. Yan et ${ }^{\wedge}$ al. also tested NiCo-nanowires deposited onto a nickel foam as a catalyst for the OER in a $1^{\wedge \wedge} \mathrm{M}$ KOH solution, ${ }^{[53]}$ with an overpotential for the OER of $337^{\wedge \wedge} \mathrm{mV}$. Han et $\mathrm{t}^{\wedge \wedge} \mathrm{al}$. produced an excellent review on transition metals $(\mathrm{Co}, \mathrm{Ni}$, and $\mathrm{Fe})$ electrocatalysts for the water oxidation reaction. ${ }^{[37]}$ Our $\mathrm{NiCo}_{2} \mathrm{O}_{4} / \mathrm{CNF}$ spinel material presents the lowest overpotential for the OER within those cited in their review. Surendran et $^{\wedge \wedge}$ al. determined that functionalizing nanostructured carbon nanofibers (CNFs) with bimetallic phosphides produces active electrodes for several reactions (oxygen reduction, oxygen evolution and hydrogen evolution). ${ }^{[54]}$ In particular, these authors developed NiCoP nanoparticles 
encapsulated in electrospun CNFs, with a current density towards the oxygen evolution reaction of $10^{\wedge \wedge} \mathrm{mA}^{\wedge} \mathrm{cm}^{<\mathrm{M}->2}$ at a very low overpotential of $268^{\wedge \wedge} \mathrm{mV}$. In this work, authors performed a comparative analysis of other studies in literature. Our $\mathrm{NiCo}_{2} \mathrm{O}_{4}$-spinel is within the best catalysts presented, excluding PtNi/CNF. Nonetheless, the measuring conditions of our experiment differ from the ones reported, generally RDE measurements either in 0.1 or $1^{\wedge \wedge} \mathrm{M} \mathrm{KOH}$ solutions, although there are some works employing foams, or carbon papers; accordingly, as previously stated, this comparison is not entirely straightforward but can be considered as a good estimation.

The $\mathrm{NiCo}_{2} \mathrm{O}_{4} / \mathrm{CNF}$ catalyst is clearly a superior oxygen evolution catalyst in comparison to the previously reported NiCo-loaded CNF, with an overpotential of $290^{\wedge \wedge} \mathrm{mV}$. As expected, the noble metal-based catalyst is not as good for the evolution of oxygen as the transition metal-based catalysts, but still presents a lower overpotential value $\left(295^{\wedge \wedge} \mathrm{mV}\right)$ in comparison to other catalysts reported in literature ${ }^{[37]}$

The difference between $\mathrm{NiCo}_{2} \mathrm{O}_{4} / \mathrm{CNF}$ and NiCo-loaded-CNF resides in the extended oxidation range for the spinel type material, leading to an increase in $\mathrm{Ni}^{3+}$ and $\mathrm{Co}^{3+}$ ions for the $\mathrm{NiCo}_{2} \mathrm{O}_{4}$. The $\mathrm{Ni}^{3+}$ ions are present in larger amount with respect to the $\mathrm{Ni}^{2+}$ ions indicating that many active sites are available for the OER. $\mathrm{Co}^{3+}$ ions are also responsible for a preferred absorption of $\mathrm{OH}^{<\mathrm{M}->}$ anions, acting as active species for the OER. ${ }^{[4]}$ Besides, it should be noted that the $\mathrm{NiCo}_{2} \mathrm{O}_{4} / \mathrm{CNF}$ has a higher amount of nitrogen in the form of pyridinic-N. Bin et ${ }^{\wedge}$ al. determined that $\mathrm{N}$ in the form of pyridinic species accepts electrons from adjacent $\mathrm{C}$ atoms. ${ }^{[55]}$ This facilitates the adsorption of $\mathrm{OH}<\mathrm{C}->$ and $\mathrm{OOH}<\mathrm{C}->$ (water oxidation intermediates), being the rds (rate-determining step) for OER in basic media.

In summary, the active sites in these catalysts could be several, depending on the reaction involved. In the case of metal sites, those are different for the ORR and the OER. $\mathrm{Ni}^{2+}$ and $\mathrm{Co}^{2+}$, along with $\mathrm{Ni}^{0}$ and $\mathrm{Co}^{0}$, are more active for the ORR; whereas, $\mathrm{Ni}^{3+}$ and $\mathrm{Co}^{3+}$ 
promote the OER. Regarding N-sites, it is believed that pyridinic $\mathrm{N}$ is active for both reactions (OER and ORR), whereas graphitic $\mathrm{N}$ seems active only in the case of the ORR, along with $\mathrm{Co}<\mathrm{C}->\mathrm{Nx}$.

\subsection{Bifunctional Behavior and Durability}

A proper rechargeable air electrode must present a good reversibility, in order to carry out both reactions with the lowest difference in the potential. The difference between the onset potential for both reactions (ORR and OER) indicates the reversibility (i.^e. bifunctional behavior of a catalytic system). This value, referred in literature as $\Delta \mathrm{E}$, has been widely employed in the specific literature for bifunctional electrodes. The spinel material shows the best reversibility of the three studied systems (see Table ${ }^{\wedge} 2<$ xtabr $2>$ ): $\Delta \mathrm{E}$ for $\mathrm{NiCo}_{2} \mathrm{O}_{4} / \mathrm{CNF}$ was $523^{\wedge} \mathrm{mV}$, followed by $\mathrm{Pd} / \mathrm{Vulcan}$ with $\Delta \mathrm{E}$ equal to $595^{\wedge} \wedge \mathrm{mV}$. The reversibility of the NiCo-loaded CNF was as high as $\Delta \mathrm{E}=633^{\wedge} \wedge \mathrm{mV}$.

Bifunctionality is a desired property in some systems such as regenerative fuel cells or metal-air batteries, but also durability is a key parameter in the lifetime of these devices. The stability of the catalyst was assessed at constant current $\left(-80^{\wedge \wedge} \mathrm{mA}^{\wedge} \mathrm{cm}^{<\mathrm{M}->2}\right)$ for $24^{\wedge \wedge} \mathrm{h}$, as depicted in Figure ${ }^{\wedge} 7<$ figr $7>$, in comparison to the NiCo-loaded CNF catalyst. As ascertained from the graph, the behavior for the NiCo-loaded CNF is more stable and with a more positive potential than for the spinel material. The initial decay in potential for the $\mathrm{NiCo}_{2} \mathrm{O}_{4} / \mathrm{CNF}$ catalyst could be due to the corrosion of carbon nanofibers, which are less graphitic and more porous than the CNF loaded with NiCo reported for comparison. In fact, the oxidative treatment at $350^{\wedge \circ} \mathrm{C}$ in air, carried out on the catalyst in order to obtain the spinel structure (see the experimental section), caused the partial degradation of the graphitic carbon structure (as clearly visible in the TEM image at low magnification, Figure $^{\wedge} 3<$ ffigr $\left.3>a\right)$. 
However, after the strong initial loss in the first hour, the decay is less pronounced with time, but still present during the $24^{\wedge} \wedge \mathrm{h}$ test, indicating a lower stability of the spinelbased catalyst compared to the NiCo-loaded CNF. It is pointed out that the cause of this instability is not ascribed to the spinel structure but to the characteristics of the carbon support. Thus, an optimization of the preparation procedure, in order to obtain the spinel structure in a one-step synthesis, is necessary to obtain a more stable catalyst. This will be the object of a future work.

\section{Conclusions}

In the present manuscript, a nickel-cobaltite spinel supported on electrospun nanofibers was successfully synthesized. Its physical-chemical features were compared to those of a previously reported NiCo-loaded CNF, with the aim of analyzing the effect of the crystallographic structure and oxidation state of both $\mathrm{Ni}$ and $\mathrm{Co}$ on the performance as bifunctional catalyst. XPS analysis revealed the main differences among both samples: NiColoaded CNF presents $\mathrm{Ni}$ and Co both in the metallic and the oxide form $\left(\mathrm{Ni}^{2+}, \mathrm{Ni}^{3+}\right.$ and $\left.\mathrm{Co}^{2+}\right)$, as well as $\mathrm{N}$ surface groups in the form of graphitic and pyridinic N. On the other hand, $\mathrm{NiCo}_{2} \mathrm{O}_{4} / \mathrm{CNF}$ presented a higher amount of $\mathrm{Ni}^{3+}$ and $\mathrm{Co}^{3+}$, and a higher amount of both graphitic and pyridinic N. Both catalysts presented similar performances for the oxygen reduction reaction. The main differences were encountered for the oxygen evolution reaction. The nickel cobaltite spinel showed an enhanced activity, due to the higher presence of $\mathrm{Ni}^{3+}$ and $\mathrm{Co}^{3+}$ groups, and a slight contribution from the higher amount of pyridinic $\mathrm{N}$, also favoring this reaction. $\mathrm{NiCo}_{2} \mathrm{O}_{4} / \mathrm{CNF}$ showed a low overpotential (at $10^{\wedge \wedge} \mathrm{mA}^{\wedge} \mathrm{cm}^{<\mathrm{M}->2}$ ), $223^{\wedge} \wedge \mathrm{mV}$, what makes it an excellent water splitting catalyst. The nickel cobaltite spinel, supported on electrospun nanofibers, showed also a remarkable reversibility $\left(\Delta \mathrm{E}=592^{\wedge \wedge} \mathrm{mV}\right)$, so it could act as a good bifunctional catalyst, although durability must be still enhanced.

\section{Experimental Section}




\section{Materials and Methods}

Nickel (II) acetate tetrahydrate $\left(\mathrm{Ni}(\mathrm{OAc})_{2} \cdot 4 \mathrm{H}_{2} \mathrm{O}\right.$, Sigma Aldrich, $\left.99.9^{\wedge} \%\right)$ and cobalt (II) acetate tetrahydrate $\left(\mathrm{Co}(\mathrm{OAc})_{2} \cdot 4 \mathrm{H}_{2} \mathrm{O}\right.$, Sigma Aldrich, $\left.99^{\wedge} \%\right)$ were used as metal precursors. Polyacrylonitrile (PAN, Sigma Aldrich, $\mathrm{Mw}=150,000)$ was used as carbon nanofibers precursor. In our previous work, ${ }^{[43]}$ the synthesis procedure by electrospinning along with the thermal treatment are reported. In order to obtain $\mathrm{NiCo}_{2} \mathrm{O}_{4} / \mathrm{CNF}$ in spinel structure form, a further thermal treatment at $350^{\wedge \circ} \mathrm{C}$ in static air for $1^{\wedge \wedge} \mathrm{h}$ was performed.

\section{Physicochemical Characterization}

Physical-chemical characterization techniques were utilized to identify the morphological and structural properties of the synthesized material. X-ray diffraction (XRD) spectra were acquired by using a Philips X-pert 3710. Differential thermal analysis (DSC) and thermogravimetric (TG) analysis were carried out by using a $409^{\wedge} \mathrm{C}$ NETZSCH-Gerätebau $\mathrm{GmbH}$ analyzer. X-ray photoelectron spectroscopy (XPS) analysis was obtained with a Physical Electronics (PHI) 5800-01 spectrometer. All the curve fittings were performed by the PHI Multipak 6.1 software. Transmission electron microscopy (TEM) was carried out using a FEI CM12 instrument. Surface area and pore size were determined by nitrogen adsorption at $77.3^{\wedge} \wedge \mathrm{K}$, from Brunauer-Emmet-Teller equation (BET) (ASAP $2020^{\wedge} \wedge$ M Micrometrics).

\section{Electrochemical Characterization}

The electrochemical experiments were performed with an Autolab PGSTAT instrument with NOVA software package connected to a 3 -electrode half-cell. The activity of $\mathrm{NiCo}_{2} \mathrm{O}_{4} / \mathrm{CNF}$ towards the oxygen reduction reaction and the oxygen evolution reaction was tested in a gas diffusion electrode. There are not many works in literature using this type of working electrode, which acts as a bridge between the fundamental studies in rotating ring disk electrode and the final device. ${ }^{[56-58]}$ To this end, an ink of the catalyst was sprayed onto a carbon cloth with a gas diffusion layer (LT 
1200WELAT, ETEK) and mounted in a gas diffusion working electrode, as described in ${ }^{\left[{ }^{[25}\right]}$ To prepare the ink, an amount of catalyst was weighed and dispersed in a solution of isopropanol and water, containing Nafion as a binder. The amount of catalyst in the ink was calculated so that the electrode had a loading of $0.5 \pm 0.02^{\wedge \wedge} \mathrm{mg}^{\wedge} \mathrm{cm}^{<\mathrm{M}-2}$ of active phase (either $\mathrm{NiCo}_{2} \mathrm{O}_{4}, \mathrm{NiCo}$ or Pd). The total amount of Nafion $\left(5^{\wedge \wedge}\right.$ wt. ${ }^{\wedge \%} \%$ solution $)$ was $30^{\wedge \wedge}$ wt.^\% of the total ink. The evolution and reduction of oxygen were evaluated in a $6^{\wedge} \mathrm{M}$ high purity $\mathrm{KOH}$ (Sigma-Aldrich, $>90^{\wedge} \%$ purity, used as received) solution flowing either $\mathrm{N}_{2}$ or $\mathrm{O}_{2}$ (respectively). The stability of the catalyst was evaluated at constant current of $<\mathrm{M}->80^{\wedge \wedge} \mathrm{mA}^{\wedge} \mathrm{cm}^{<\mathrm{M}->2}$ for $24^{\wedge} \mathrm{h}$, evaluating the potential decay with time.

\section{Acknowledgements}

The research leading to these results has received funding from the "Accordo di Programma CNR-MiSE, Gruppo tematico Sistema Elettrico Nazionale e Progetto: Sistemi elettrochimici per l'accumulo di energia".

\section{Conflict of Interest}

The authors declare no conflict of interest.

$<$ lit1 ><jnl>T.^^M. Gür, Energy Environ. Sci. 2018, 11, 2696--2767</jnl>.

$<$ lit2 $><\mathrm{jnl}>\mathrm{C} . \mathrm{Lo}^{\wedge \wedge}$ Vecchio, A. ${ }^{\wedge} \mathrm{S}$. Aricò, G. Monforte, V. Baglio, Renewable Energy 2018, $120,342--349</$ jnl $>$.

$<$ lit3 $><$ jnl $>$ T. Sadhasivam, K. Dhanabalan, S.-H. Roh, T.-H. Kim, K.-W. Park, S. Jung, M.^^D. Kurkuri, H.-Y. Jung, Int. J. Hydrogen Energy 2017, 42, 4415--4433</jnl>.

$<$ lit4><jnl $>$ Y.-J. Wang, B. Fang, X. Wang, A. Ignaszak, Y. Liu, A. Li, L. Zhang, J. Zhang, Prog. Mater. Sci. 2018, 98, 108--167</jnl $>$.

$<$ lit5 $><$ jnl $>$ S. Altmann, T. Kaz, K.^^A. Friedrich, Electrochim. Acta 2011, 56, 4287-$4293</$ jnl $>$. 
$<$ lit6><jnl $>$ B. Paul, J. Andrews, Renewable Sustainable Energy Rev. 2017, 79, 585-$599</$ jnl $>$.

$<$ lit7 $><$ jnl $>$ X. Zhang, X. Cheng, Q. Zhang, J. Energy Chem. 2016, 25, 967--984</jnl $>$.

$<$ lit8 $><$ jnl $>$ S. Dresp, P. Strasser, ChemCatChem 2018, 10, 4162--4171</jnl $>$.

$<$ lit9 $><$ jnl $>$ R.^^D. McKerracher, H.^^A. Figueredo-Rodríguez, J.^^O. Avila-Alejo, K.

Kwasnicki, C. ${ }^{\wedge} \mathrm{P} . \mathrm{De}^{\wedge \wedge}$ León, C. Alegre, V. Baglio, A. ${ }^{\wedge} \mathrm{S}$. Aricò, F.^^C. Walsh, $J$. Electrochem. Soc. 2018, 165, A1254--A1262</jnl $>$.

$<$ lit10 $><$ jnl $>$ S.^^A. Grigoriev, P. Millet, K. ${ }^{\wedge}$ A. Dzhus, H. Middleton, T. ${ }^{\wedge}$ O. Saetre, V.^^N.

Fateev, Int. J. Hydrogen Energy 2010, 35, 5070--5076</jnl $>$.

$<$ lit11 $><$ jnl $>$ V. Neburchilov, H. Wang, J.^^J. Martin, W. Qu, J. Power Sources 2010, 195, $1271--1291<$ jnl $>$.

$<$ lit12 $><$ jnl $>$ P. Clechet, C. Martelet, J.^^R. Martin, R. Olier, Electrochim. Acta 1979, 24, $457--461</$ jnl $>$.

$<$ lit13 $><$ jnl $>$ Y. He, J. Zhang, G. He, X. Han, X. Zheng, C. Zhong, W. Hu, Y. Deng, Nanoscale 2017, 9, 8623--8630</jnl $>$.

$<$ lit14 $><$ jnl $>$ J. ${ }^{\wedge}$ C. Cruz, V. Baglio, S. Siracusano, R. Ornelas, L. ${ }^{\wedge}$ G. Arriaga, V. Antonucci, A.^^S. Aricò, Int. J. Hydrogen Energy 2012, 37, 5508--5517</jnl>.

$<$ lit15 $><$ jnl $>$ C. Alegre, A. Stassi, E. Modica, C. Lo ${ }^{\wedge \wedge}$ Vecchio, A. ${ }^{\wedge}$ S. Aricò, V. Baglio, $R S C$ $A d v .2015,5,25424--25427</$ jnl $>$.

$<$ lit16 $><$ jnl $>$ E. Antolini, ACS Catal. 2014, 4, 1426--1440</jnl $>$.

$<$ lit17 $><$ jnl $>$ A. Paulraj, Y. Kiros, M. Göthelid, M. Johansson, A.^^R. Paulraj, Y. Kiros, M.

Göthelid, M.^^B. Johansson, Catalysts 2018, $8,328</$ jnl $>$. 
$<$ lit18><jnl $>$ J.-I. Jung, M. Risch, S. Park, M.^^G. Kim, G. Nam, H.-Y. Jeong, Y. Shao-Horn, J. Cho, Energy Environ. Sci. 2016, 9, 176--183</jnl $>$.

$<$ lit19 $><$ jnl $>$ D. Chen, C. Chen, Z.^^M. Baiyee, Z. Shao, F. Ciucci, Chem. Rev. 2015, 115, 9869--921</jnl $>$.

$<$ lit20 $><$ jnl $>$ C. Alegre, E. Modica, A.^^S.^^S. Aricò, V. Baglio, J. Electroanal. Chem. 2016, $808,412--419</$ jnl $>$.

$<$ lit21 $><$ jnl $>$ M.^^E. Hamzehie, L. Samiee, M. Fattahi, A.^^A. Seifkordi, F. Shoghi, A.

Maghsodi, Renewable Energy 2015, 77, 558--570</jnl $>$.

$<$ lit22 $><$ jnl $>$ Y. Cheng, S. He, J. Veder, R. De ${ }^{\wedge \wedge}$ Marco, S. Yang, S. Ping^^Jiang,

ChemElectroChem 2019, 6, 3478--3487</jnl >.

$<$ lit23 $><$ jnl $>$ A. Martínez-Lázaro, A. Rico-Zavala, F.^^I. Espinosa-Lagunes, J. Torres-

González, L. Álvarez-Contreras, M. ${ }^{\wedge} P$. Gurrola, L.^^G. Arriaga, J. Ledesma-García,

E. Ortiz-Ortega, J. Power Sources 2019, 412, 505--513</jnl $>$.

$<$ lit24 $><$ jnl $>$ A. Aijaz, J. Masa, C. Rösler, W. Xia, P. Weide, A. ${ }^{\wedge}{ }^{\wedge}{ }^{\wedge}$ R. Botz, R. ${ }^{\wedge}$ A. Fischer,

W. Schuhmann, M. Muhler, Angew. Chem. Int. Ed. 2016, 55, 4087--91</jnl>.

$<$ lit25 $><$ jnl $>$ C. Alegre, C. Busacca, O. Di^^${ }^{\wedge}$ Blasi, V. Antonucci, A. ${ }^{\wedge}$ S. Aricò, A. Di^^${ }^{\wedge}$ Blasi,

V. Baglio, J. Power Sources 2017, 364, 101--109</jnl $>$.

$<$ lit26 $><$ jnl $>$ D.^^U. Lee, J.-Y. Choi, K. Feng, H.^^W. Park, Z. Chen, Adv. Energy Mater.

2014, 4, 1301389</jnl $>$.

$<$ lit27><jnl $>$ S. Mao, Z. Wen, T. Huang, Y. Hou, J. Chen, Energy Environ. Sci. 2014, 7, 609-$616</$ jnl $>$.

$<$ lit28 $><$ jnl $>$ J. Sanetuntikul, S. Hyun, P. Ganesan, S. Shanmugam, J. Mater. Chem. A 2018, 6, 24078--24085</jnl $>$. 
$<$ lit29 $><$ jnl $>$ R. Gao, Y. Yin, F. Niu, A. Wang, S. Li, H. Dong, S. Yang, ChemElectroChem 2019, 6, 1824-- $1830</$ jnl $>$.

$<$ lit30 $><$ jnl $>$ H. Shui, T. Jin, J. Hu, H. Liu, ChemElectroChem 2018, 5, 1401--1406</jnl $>$. $<$ lit31 ><jnl>J.^^M. Luque-Centeno, M.^^V. Martínez-Huerta, D. Sebastián, G. Lemes, E. Pastor, M.^^J. Lázaro, Renewable Energy 2018, 125, 182--192</jnl >.

$<$ lit32 $><$ jnl $>$ Y..$^{\wedge}$ J. Sa, K. Kwon, J.^^${ }^{\wedge}$. Cheon, F. Kleitz, S.^^H. Joo, J. Mater. Chem. A 2013, $1,9992</$ jnl $>$.

$<$ lit33 $><$ jnl $>$ A. $.^{\wedge} H .{ }^{\wedge \wedge}$ A..$^{\wedge}$ A. Monteverde ${ }^{\wedge}$ Videla, P. Stelmachowski, G. Ercolino, S.

Specchia, J. Appl. Electrochem. 2017, 47, 295--304</jnl $>$.

$<$ lit34><jnl $>$ X. Liu, M. Park, M.^^G. Kim, S. Gupta, G. Wu, J. Cho, Angew. Chem. Int. Ed. 2015, 54, 9654--9658</jnl $>$.

$<$ lit35 $><$ jnl $>$ M. Prabu, K. Ketpang, S. Shanmugam, Nanoscale 2014, 6, 3173</jnl $>$. $<$ lit36><jnl $>$ D. Pletcher, X. Li, S. ${ }^{\wedge}$ W. ${ }^{\wedge}$ T. Price, A.^^${ }^{\wedge}$. Russell, T. Sönmez, S.^^J.

Thompson, Electrochim. Acta 2016, 188, 286--293</jnl>.

$<$ lit37><jnl $>$ L. Han, S. Dong, E. Wang, Adv. Mater. 2016, 28, 9266--9291</jnl $>$.

$<$ lit38 $><$ jnl $>$ C. Yu, J. Lu, L. Luo, F. Xu, P.^^K. Shen, P. Tsiakaras, S. Yin, Electrochim. Acta 2019, 301, 449--457</jnl>.

$<$ lit39 $><$ jnl $>$ A. ${ }^{\wedge}$ K. Samantara, S. Kamila, A. Ghosh, B.^^K. Jena, Electrochim. Acta 2018, $263,147--157</$ jnl $>$.

$<$ lit40 $><$ jnl $>$ Z. Zhao, M. Li, L. Zhang, L. Dai, Z. Xia, Adv. Mater. 2015, 27, 6834-$6840</$ jnl $>$.

$<$ lit41 $><$ jnl $>$ R. Wang, Z. Chen, N. Hu, C. Xu, Z. Shen, J. Liu, ChemElectroChem 2018, 5, $1745--1763</$ jnl $>$. 
$<$ lit42 $><$ jnl $>$ P. Li, H. Jang, J. Zhang, M. Tian, S. Chen, B. Yuan, Z. Wu, X. Liu, J. Cho, ChemElectroChem 2019, 6, 393--397</jnl $>$.

$<$ lit43 $><$ jnl $>$ C. Alegre, E. Modica, A. Di^^${ }^{\wedge}$ Blasi, O. Di^^${ }^{\wedge}$ Blasi, C. Busacca, M. Ferraro,

A.^^S. Aricò, V. Antonucci, V. Baglio, Renewable Energy 2018, 125, DOI

10.1016/j.renene.2018.02.089</jnl > .

$<$ lit44 $><$ jnl $>$ M.-S. Wu, Y.-R. Zheng, G.-W. Lin, Chem. Commun. 2014, 50, 8246</jnl $>$.

$<$ lit45 $><$ jnl $>$ V. Ivanov, J.^^B. Nagy, P. Lambin, A. Lucas, $X .^{\wedge} \mathrm{F} .{ }^{\wedge}{ }^{\wedge} \mathrm{X} .{ }^{\wedge} \mathrm{B}$. Zhang,

X.^^F.^^X.^^B. Zhang, D. Bernaerts, G. Van^^${ }^{\wedge}$ Tendeloo, S. Amelinckx, J.

Van^^${ }^{\wedge}$ Landuyt, Chem. Phys. Lett. 1994, 223, 329--335</jnl $>$.

$<$ lit46 $><$ jnl $>$ C. Zhang, T. Kuila, N. ${ }^{\wedge} H$ H. Kim, S. ${ }^{\wedge} H$. Lee, J.^^H. Lee, Carbon 2015, 89, 328$-339</$ jnl $>$.

$<$ lit47><jnl $>$ C. Alegre, C. Busacca, A. Di^^${ }^{\wedge}$ Blasi, O. Di^^${ }^{\wedge}$ Blasi, A. ${ }^{\wedge}$ S. Aricò, V. Antonucci,

E. Modica, V. Baglio, J. Energy Storage 2019, 23, 269--277</jnl >.

$<$ lit48 $><$ jnl $>$ L. Zhang, Z. Su, F. Jiang, L. Yang, J. Qian, Y. Zhou, W. Li, M. Hong, Nanoscale 2014, 6, 6590--6602</jnl $>$.

$<$ lit49 $><$ jnl $>$ L. Qian, L. Gu, L. Yang, H. Yuan, D. Xiao, Nanoscale 2013, 5, 7388</jnl $>$. $<$ lit50 $><$ jnl $>$ Y. Xue, Y. Wang, H. Liu, X. Yu, H. Xue, L. Feng, Chem. Commun. 2018, 54, 6204--6207</jnl $>$.

$<$ lit51 $><$ jnl $>$ J.^^ L. Gautier, E. Rios, M. Gracia, J.^^F. Marco, J.^^R. Gancedo, Thin Solid Films 1997, 311, 51--57</jnl $>$.

$<$ lit52 $><$ jnl $>$ S.-H. Bae, J.-E. Kim, H. Randriamahazaka, S.-Y. Moon, J.-Y. Park, I.-K. Oh, Adv. Energy Mater. 2017, 7, 1601492</jnl $>$. 
$<$ lit53 $><$ jnl $>$ X. Yan, K. Li, L. Lyu, F. Song, J. He, D. Niu, L. Liu, X. Hu, X. Chen, ACS Appl. Mater. Interfaces 2016, 8, 3208--3214</jnl $>$.

$<$ lit54 $><$ jnl $>$ S. Surendran, S. Shanmugapriya, A. Sivanantham, S. Shanmugam, R.

Kalai $^{\wedge \wedge}$ Selvan, Adv. Energy Mater. 2018, $8,1800555</$ jnl $>$.

$<$ lit55 $><$ jnl $>$ H. Bin ${ }^{\wedge}$ Yang, J. Miao, S.-F. Hung, J. Chen, H. ${ }^{\wedge}$ B. Tao, X. Wang, L. Zhang, R.

Chen, J. Gao, H.^^M. Chen, Sci. Adv. 2016, 2, e1501122</jnl $>$.

$<$ lit56 $><$ jnl $>$ R. ${ }^{\wedge}$ D. McKerracher, C. Alegre, V. Baglio, A. ${ }^{\wedge}$ S. Aricò, C. Ponce ${ }^{\wedge} \mathrm{de}^{\wedge \wedge}$ León,

F. Mornaghini, M. Rodlert, F.^^C. Walsh, Electrochim. Acta 2015, 174, 508-$515</$ jnl $>$.

$<$ lit57><jnl $>$ X. Li, D. Pletcher, A. ${ }^{\wedge}$ E. Russell, F. ${ }^{\wedge}$ C. Walsh, R. ${ }^{\wedge}$ G. ${ }^{\wedge \wedge}$ A. Wills, S. ${ }^{\wedge}$ F.

Gorman, S.^^W.^^T. Price, S.^^J. Thompson, Electrochem. Commun. 2013, 34, 228-$230</$ jnl $>$.

$<$ lit58><jnl $>$ D. Sebastián, C. Alegre, M. ${ }^{\wedge}$ E. Gálvez, R. Moliner, M.^^J. Lázaro, A. ${ }^{\wedge}$ S.

Aricò, V. Baglio, J. Mater. Chem. A 2014, 2, 13713</jnl $>$.

Table $^{\wedge \wedge} 1 \quad$ Atomic concentration for $\mathrm{C}, \mathrm{N}, \mathrm{O}, \mathrm{Co}$ and $\mathrm{Ni}$.

\begin{tabular}{|c|c|c|c|c|c|}
\hline Sample & $\mathrm{C} 1$ & N1 & $\mathrm{O} 1^{\wedge}$ & $\mathrm{Co}$ & $\mathrm{Ni} 2 \mathrm{p}$ \\
\hline & $\wedge^{\wedge} \mathrm{s}$ & $\wedge^{\wedge} \mathrm{S}$ & $\wedge_{\mathrm{s}}$ & $2 p$ & \\
\hline $\mathrm{NiCo}_{2} \mathrm{O}_{4} / \mathrm{C}$ & 70 & 3.7 & 14. & 7.5 & 3.8 \\
\hline $\mathrm{NF}$ & 2 & & 8 & & \\
\hline NiCo- & 90. & 3.1 & 4.7 & 1.2 & 0.3 \\
\hline loaded/CNF & 7 & & & & \\
\hline
\end{tabular}

Table $^{\wedge \wedge}$ Electrochemical parameters determined from LSVs: onset potential, overpotential, and reversibility $\left(\Delta \mathrm{E}<\mathrm{C}=>\mathrm{E}_{\mathrm{OER}}-\mathrm{E}_{\mathrm{ORR}}\right)$.

\begin{tabular}{|c|c|c|c|c|c|}
\hline Catalyst & $\mathrm{E}_{\mathrm{ORR}}{ }^{[\mathrm{a}]}$ & $\eta_{\text {ORR }}{ }^{[b]}$ & $\mathrm{E}_{\mathrm{OER}}$ & $\eta_{\mathrm{OER}}{ }^{[\mathrm{b}]}$ & $\Delta \mathrm{E}$ \\
\hline
\end{tabular}




\begin{tabular}{lccccc}
\hline & \multicolumn{5}{c}{ [c] } \\
\cline { 3 - 5 } $\mathrm{Pd} /$ Vulcan & 0.930 & 0.300 & 1.525 & 0.295 & 595 \\
NiCo-loaded & 0.887 & 0.343 & 1.520 & 0.290 & 633 \\
$\mathrm{CNF}$ & & & & & \\
$\mathrm{NiCo}_{2} \mathrm{O}_{4} / \mathrm{CNF}$ & 0.861 & 0.369 & 1.453 & 0.223 & 592 \\
\hline
\end{tabular}

[a] Onset potential (V vs. RHE) for the ORR calculated at -- $1^{\wedge \wedge} \mathrm{mA}^{\wedge} \mathrm{cm}^{<\mathrm{M}->2}$. [b] $\eta$ overpotential for the ORR (V vs. RHE). [c] Potential for the OER calculated at -$10^{\wedge \wedge} \mathrm{mA}^{\wedge} \mathrm{cm}^{<\mathrm{M}->2}$.

Figure $^{\wedge} 1 \quad \mathrm{NiCo}_{2} \mathrm{O}_{4} / \mathrm{CNF}$ 's XRD profile.

Figure $^{\wedge} 2 \quad$ TG/DSC analysis patterns of both NiCo-loaded CNF (dotted line); $\mathrm{NiCo}_{2} \mathrm{O}_{4} / \mathrm{CNF}$ (solid line); (gas: air).

Figure ${ }^{\wedge} 3 \quad$ TEM images (a--c) and particle size distribution (d) of $\mathrm{NiCo}_{2} \mathrm{O}_{4} / \mathrm{CNF}$.

Figure ${ }^{\wedge} 4 \quad$ XPS deconvolution curves of a) O1s, b) C1s, c) N1s orbitals for $\mathrm{NiCo}_{2} \mathrm{O}_{4} / \mathrm{CNF}$ and d) histogram of the corresponding nitrogen groups content in the $\mathrm{NiCo}_{2} \mathrm{O}_{4} / \mathrm{CNF}$ and NiCo-loaded CNF.

Figure $^{\wedge} 55$ XPS deconvolution curves of a) Ni2p orbitals, b) Co2p orbitals and c) histogram of the corresponding nickel and cobalt species content for $\mathrm{NiCo}_{2} \mathrm{O}_{4} / \mathrm{CNF}$ and NiCo-loaded CNF.

Figure $^{\wedge} 6 \quad$ LSVs for the NiCo-based materials in comparison to a noble metal-based catalyst, Pd/Vulcan A) ORR; B) OER. C) Overpotential at $10^{\wedge \wedge} \mathrm{mA}^{\wedge} \mathrm{cm}^{<\mathrm{M}->2}$ for the OER.

Figure ${ }^{\wedge} 7$ Stability test for both NiCo-loaded $\mathrm{CNF}$ and $\mathrm{NiCo}_{2} \mathrm{O}_{4} / \mathrm{CNF}$. Constant current $=<\mathrm{M}->80^{\wedge \wedge} \mathrm{mA}^{\wedge} \mathrm{cm}^{<\mathrm{M}->2}$ flowing $\mathrm{O}_{2}$ in the electrolyte. 